\title{
İleri evre KY'de sakubitril/valsartan'ın yeri var mı?
}

\author{
Dr. Sanem Nalbantgil
}

Ege Üniversitesi Tıp Fakültesi, Kardiyoloji Anabilim Dalı, İzmir

Yakın zamana kadar ileri evre kalp yetersizliği (KY), tedaviye refrakter NYHA IV olan hastalar olarak tanımlanmaktaydı. Ancak son yılarda gerek $\mathrm{Ku}-$ zey Amerika, gerekse Avrupa'da ileri evre KY için yeni tanımlar getirilmiş, NYHA III olan hastaların belli kriterleri karşıladıkları takdirde ileri evre KY hastası olarak tanımlanması gerektiği vurgulanmıştır. ${ }^{[1]}$ Ancak KY ile yapılan çalışmaları değerlendirdiğgimizde bu yeni tanım ile hastaların demografik verilerinin ortaya konmadığını görmekteyiz. Bu bölümde çalışmalarda yer alan yalnız NYHA IV değil, NYHA III hastalarının verilerine de yer verilmiştir. Aşağıdaki çalışmalar değerlendirildiğinde dahil edilen hastaların \%40'tan fazlası çalışma öncesi KY nedenli hospitalizasyon tanımlamaktadır. Dolayısıyla ileri evre KY hasta sayısını sadece NYHA IV hastaları ile kısitlamanın doğru olmadığını düşünmek yanlış olmayacaktır. Ancak bu hastaların ne kadarının ileri evre KY hastas1 olduğunu söyleyebilmek mümkün değildir. Çünkü çalışmalarda yer alan NYHA IV olarak tanımlanmış hastaların oranı oldukça düşüktür.

Sakubutril/Valsartan tedavisinin etkinliğinin ortaya konduğu PARADIGM HF çalışmasının verilerine bakıldığında NYHA IV olan hastaların oranının $\% 1$ 'in altında, NYHA III olan hastaların ise ancak hasta popülasyonun \%25'ini oluşturduğunu görmekteyiz. Ortalama BNP değeri çalışma grubunda 255 $\mathrm{pg} / \mathrm{ml}$, NT-proBNP değeri ise $1631 \mathrm{pg} / \mathrm{ml}$, en yüksek NT-proBNP düzeyi ise $3154 \mathrm{pg} / \mathrm{ml}$ olarak bildirilmiştir. Bu bulgular bize bu çalışmaya dahil edilen ileri evre KY hasta sayısının yüksek olmadığını düşündürmektedir. Yine çalışmaya sistolik kan basıncı taramada $100 \mathrm{mmHg}$, randomizasyonda $95 \mathrm{mmHg}$ değerinin altında olan hastalar dahil edilmemiştir. $\mathrm{Bu}$ kriter ile sistolik kan basıncı düşük seyreden ileri evre hastaların dışlandığını düşünebiliriz. ${ }^{[2]}$ Çalışmanın primer sonlanımı (kardiyovasküler ölüm ve KY nedeniyle hospitalizasyon) fonksiyonel sinıflar arasında fark olmaksızın olumlu sonuçlanmıştır. Subgrup analizine bakıldığında ise primer sonlanım NYHA III ve IV olan hastalarda anlamlı olarak daha kötü iken $(\mathrm{p}=0.03)$ iken kardiyovasküler ölüm için fark ortaya konamamıştır. ${ }^{[2]}$

İleri evre hasta grubu verilerinin görülebileceği diğer bir çalışma TRANSITION çalışmasıdır. ${ }^{[3]} \mathrm{Bu}$ çalışmaya akut dekompanse KY nedeni ile hastaneye yatırılan 1000'den fazla hasta dahil edilmiştir. Hastaların bir grubu hastaneden çıkmadan önce diğer grubu ise taburcu olduktan sonra 14 gün içinde sakubutril/ valsartan tedavisini almaya başlamışlardır. Tedavi hastalara hemodinamik stabilizasyon sağlandıktan sonra verilmiştir. Demografik verilere bakıldığında tedavi başlandığında hospitalizasyon anamnezine rağmen hastaların yaklaşık \%64'ü NYHA II, \%35'i NYHA III ve ancak \%1'i NYHA IV olarak tanımlanmıştır. $\mathrm{Bu}$ nedenle hastaların ne kadarının ileri evre KY hastası olduğu net değildir. Tedaviye alınan hastalarda sistolik kan basıncının ortalama $124 \pm 14.0$ mmHg olduğu akılda tutulmalıdır. Hastaların \%85'inden fazlasında 24/26 mg ile tedaviye başlanmış ve 10 haftada $\% 50$ hasta maksimal doza ulaşabilmiştir. Tedavi boyunca hastaların yaklaşık \%67'inde ilaca bağ11 yan etki (hipotansiyon: \%13, hiperkalemi, böbrek fonksiyonlarında bozulma, KY, akut böbrek yetmezliği) tanımlanmıştır. Çalışma akut KY ile hastaneye yatan hastalarda (ne kadarının ileri evre olduğu net değil) hasta stabil olduktan sonra başlanan ARNİ tedavisinin güvenilir olduğunu ortaya koymuştur. ${ }^{[3]}$

Akut KY hastalarında yapılan diğer bir çalışma ise PIONEER HF çalışmasıdır. ${ }^{[4]} \mathrm{Bu}$ çalışmada da 800 'den fazla akut dekompanse KY nedeni ile hospitalize edilmiş hastalarda, dekompansasyon sonrası başlanan sakubitril/valsartan veya enalapril tedavisinin 4 ve 8 . haftalarda natriüretik peptid düzeyine olan etkisi araştırılmıştır. İleri evre KY hastası olarak kabul edilebilecek çalışma popülasyonundaki hastaların yaklaşık \%9'u NYHA IV, \%65'i NYHA III ve \%27'si NYHA II fonksiyonel kapasiteye sahipti. Bu çalışma, 
en yüksek oranda ileri evre KY hastasının dahil edildiği çalışma olarak kabul edilebilir. Hastaların tarama sirasında ortalama NT-proBNP değeri $4821 \mathrm{pg} / \mathrm{ml}$ ve randomizasyon sırasında NT-proBNP değeri $2883 \mathrm{pg} /$ $\mathrm{ml}$ olarak bildirilmiştir. Hastalara ilaç tedavisinin ne zaman başlandığ bil olan, son 6 saat içinde sistolik kan basıncı $\geq 100$ mmHg seyreden, IV diüretik tedavi ihtiyacında artış olmayan, son altı saat içinde vazodilatör tedavi almayan ve son 24 saat içinde inotrop ihtiyacı olmayan hastalar çalışmaya dahil edilmiştir. Sekiz hafta sonunda yaklaşık \%55 hastada hedef doza ulaşılmıştır. Sonucu ARNİ tedavisi lehine olumlu çıkan çalışmada $\% 20$ olguda yan etkiler nedeniyle tedavi sonlandirılmıştır. Hipotansiyon yaklaşık \%15 hastada gelişmiştir. Bu çalışmanın kardiyovasküler olayları inceleyen bir analizinde ise ARNI tedavisinin enalapril ile karşılaştırıldığında kardiyovasüler ölüm ve KY nedeniyle hospitalizasyon üzerine istatistiksel olarak anlamlı olan olumlu etkisi ortaya konmuştur. ${ }^{[5]}$

Bu üç çalışmanın sonucu olarak düşük ejeksiyon fraksiyonlu ileri evre KY hastalarında sakubitril/valsartan tedavisinin başlanabilece $\breve{g} i$ ve bu tedaviden hastaların yarar să̆layabilece $\breve{g} i$ anlaşılmaktadır. Ancak tedaviye başlamadan önce hastaların klinik ve hemodinamik olarak stabil olmaları önemlidir. Yine tedavi başlanırken KAN BASINCI'nın $\geq 100 \mathrm{mmHg}$ olmasina dikkat edilmelidir. Gelişebilecek yan etkiler, özellikle hipotansiyon, yakından takip edilmelidir. $\mathrm{Bu}$ hastalara EN DÜŞÜK doz olan 24/26 mg ile başlamak akılcı olacaktır. Hastanın kliniği izin verdikçe maksimal doza ulaşmak hedeflenmelidir.

Korunmuş ejeksiyon fraksiyonlu KY hastalarındaki veriler kısıtlıdır. PARAGON çalışması konu ile ilgili en kapsamlı çalışmadır. ${ }^{[6]}$ Çalışmaya alınan hastaların yaklașık \%20'si NYHA III ve \%1'den azı NYHA IV fonksiyonel kapasiteye sahip hastalardı. Diüretik veya vazodilatör tedaviye ihtiyaç duyan akut dekompanse KY hastaları çalışmadan dışlanmıştır. Dolayısıyla bu çalışmaya dahil edilen ileri evre KY hasta sayısının yüksek olduğu söylenemez. Valsartan ile sakubitril/ valsartan tedavilerinin karşılaştırıldığı bu çalışmanın primer sonlanımı olan kardiyovasküler ölüm ve KY nedenli hospitalizasyon oranları sakubitril/valsartan ile daha iyi görünmekle beraber iki grup arasında anlamlı fark bulunamamıştır. Fonksiyonel kapasiteye göre yapılan subgrup analizinde NYHA III ve IV olan hastaların NYHA I ve II olanlarla karşılaştırıldığında tedaviden daha fazla yarar gördükleri bildirilmiştir (NYHA III ve IV için risk oranı 0.79 (0.59-1.06) ve NYHA I ve II için risk oranı 0.90 (0.76-1.65). İleri evre KY olan hastalarda ilacin olumlu etkisini ortaya koyan veriler halen yetersizdir. ${ }^{[6]}$ İzole ileri sağ KY olan hastalarda ARNİ tedavisinin etkisini gösteren bir çalışma halen mevcut değildir.

Sonuç olarak, sakubitril/valsartan'ın ileri evre KY'de etkinlik ve güvenliğine ilişkin yeterli verinin olmadığı söylenebilir. Bunun için NYHA IV hasta grupları veya ileri evre KY tanımlarına uygun hastaları içeren çalışmalara ihtiyaç vardır. Ancak ACEİ/ ARB, beta-bloker ve MRA'yı içeren optimal medikal tedaviye yanıt alınamayan ileri evre KY olgularında, sistolik kan basıncı ve böbrek fonksiyonları dikkate alınarak düşük dozdan başlamak şartı ile sakubitril/ valsartan tedavisi verilebilir.

\section{Kaynaklar}

1. Crespo-Leiro MG, Metra M, Lund LH, Milicic D, Costanzo MR, Filippatos G, et al. Advanced heart failure: a position statement of the Heart Failure Association of the European Society of Cardiology. Eur J Heart Fail 2018;20:1505-35.

2. McMurray JJ, Packer M, Desai AS, Gong J, Lefkowitz MP, Rizkala AR, et al. Angiotensin-neprilysin inhibition versus enalapril in heart failure. N Engl J Med 2014;371:993-1004.

3. Wachter R, Senni M, Belohlavek J, Straburzynska-Migaj E, Witte $\mathrm{KK}$, Kobalava Z, et al. Initiation of sacubitril/valsartan in haemodynamically stabilised heart failure patients in hospital or early after discharge: primary results of the randomised TRANSITION study. Eur J Heart Fail 2019;21:998-1007.

4. Velazquez EJ, Morrow DA, DeVore AD, Duffy CI, Ambrosy AP, McCague K, et al. Angiotensin-Neprilysin Inhibition in Acute Decompensated Heart Failure. N Engl J Med 2019;380:539-48.

5. DeVore AD, Braunwald E, Morrow DA, Duffy CI, Ambrosy AP, Chakraborty $\mathrm{H}$, et al. Initiation of Angiotensin-Neprilysin Inhibition After Acute Decompensated Heart Failure: Secondary Analysis of the Open-label Extension of the PIONEER-HF Trial. JAMA Cardiol 2019;5:202-7.

6. Solomon SD, McMurray JJV, Anand IS, Ge J, Lam CSP, Maggioni $\mathrm{AP}$, et al. Angiotensin-Neprilysin Inhibition in Heart Failure with Preserved Ejection Fraction. N Engl J Med 2019;381:1609-20. 